\title{
TINGKAT KEPUASAN GOFOOD PARTNER TERHADAP SISTEM KEMITRAAN PADA MASA PANDEMI COVID-19 DI KOTA SURABAYA
}

\author{
GOFOOD PARTNER SATISFACTION LEVEL \\ ON THE PARTNERSHIP SYSTEM DURING THE PANDEMIC COVID-19 \\ IN SURABAYA CITY
}

\author{
APRILIA DWI PERMATA SARI, SRI WIDAYANTI*, TEGUH SOEDARTO \\ Fakultas Pertanian, Universitas Pembangunan Nasional "Veteran" Jawa Timur \\ *E-mail : widayanti123@yahoo.com
}

\begin{abstract}
ABSTRAK
Pandemi covid-19 memberikan dampak terhadap sektor agroindustri salah satunya pengolahan makanan dan minuman atau yang lebih dikenal dengan bisnis kuliner. Untuk bertahan di kondisi ini, alternatif yang cukup menjanjikan adalah layanan pesan antar makanan. Gofood merupakan layanan pesan antar makanan buatan Indonesia yang menggunakan media tukang ojek sebagai pengantar makanan. Tujuan penelitian ini adalah mengukur tingkat kepuasan gofood partner yang terdiri dari mitra merchant dan mitra driver terhadap sistem kemitraan pada masa pandemi covid-19 di Kota Surabaya. Pengukuran tingkat kepuasan gofood partner digunakan kerangka kerja PIECES, pengukuran yang didasarkan pada 6 aspek yaitu aspek Performance, Information, Economic, Control \& Security, Efficiency, dan Services. Hasil analisis PIECES menunjukkan bahwa pengukuran tingkat kepuasan gofood partner berada dalam kategori puas, baik mitra merchant maupun mitra driver.
\end{abstract}

Kata Kunci: Tingkat Kepuasan, Mitra Gofood, Pandemi Covid-19

\begin{abstract}
The pandemic covid-19 has an impact on one of the agroindustrial sector, which is in processing level for food and beverage known as the culinary business. To survive in this condition, a promising alternative is food delivery platform. Gofood is an Indonesian food delivery platform that uses motorcycle taxi as food delivery media. The purpose of this study is to measure the level of gofood partner satisfaction consisting of merchant partner and driver partner on the partnership system during the pandemic covid-19 in Surabaya. Measurement of the satisfaction level of gofood partner are used by the PIECES framework, which measure based on six aspect, Performance, Information, Economic, Control \& Security, Efficiency, and Services. The results of the PIECES analysis showed the satisfaction level of gofood partner is in the satisfied category, both of merchant partner and driver partner.
\end{abstract}

Kewords: Partner Satisfaction, Gofood Partner, Pandemic Covid-19

\section{PENDAHULUAN}

Pandemi covid-19 merupakan permasalahan yang sedang dihadapi seluruh dunia mendorong pemerintah Indonesia membuat kebijakan mengenai Pembatasan Sosial Berskala Besar (PSBB) sebagai upaya pencegahan penyebaran covid-19.

Kebijakan

tersebut mengakibatkan kegiatan masyarakat menjadi sangat terbatas sehingga memberikan dampak negatif terhadap perekonomian masyarakat, meningkatkan jumlah pengangguran, menurunkan kegiatan jual-beli, dan melumpuhkan 
pertumbuhan (Lee, 2020). Dampak tersebut juga dirasakan pelaku agroindustri khususnya pada sektor pengolahan makanan dan minuman atau yang lebih dikenal dengan bisnis kuliner.

Bisnis kuliner adalah industri yang paling terdampak dengan adanya pandemi covid-19 (Severson \& Bellany, 2020). Untuk bertahan di kondisi ini, pelaku bisnis diharuskan memanfaatkan alternatif yang tersedia dalam menjangkau konsumen dan menstabilkan pendapatan. Alternatif yang cukup menjanjikan adalah layanan pesan antar makanan. Platform pesan antar makanan dapat berperan penting dalam mengurangi dampak negatif akibat perubahan kondisi yang menyebabkan perekonomian menurun (Raj et al., 2020). Potensi layanan pesan antar makanan cukup tinggi seiring dengan peningkatan pengguna internet di Indonesia tiap tahun. Menurut data BPS, pengguna internet di Indonesia pada tahun 2019 sebesar 175,4 juta atau $65 \%$ dari total penduduk Indonesia.

Gofood merupakan layanan pesan antar makanan yang tersedia pada aplikasi gojek buatan Indonesia dan menjadi fitur yang paling banyak dimanfaatkan oleh masyarakat Indonesia (Dewi, 2018). Gofood memberikan dampak positif seperti terbukanya lapangan pekerjaan baru sehingga dapat menjadi mata pencaharian bagi masyarakat Indonesia (Sari \& Zaini, 2020). Fitur yang berada di bawah perusahaan Gojek ini berpotensi dalam menggerakkan kembali kegiatan perekonomian. Di tengah banyaknya perusahaan industri yang mengurangi pekerjanya, gofood masih terus membuka lapangan pekerjaan melalui sebuah kemitraan. Berbagai upaya dilakukan gofood dalam melaksanakan layanan kemitraan yang biasanya dilakukan secara langsung, kini diubah menjadi daring agar tetap mampu memberikan layanan terbaik tanpa kontak langsung. Pada Januari 2020, gofood melakukan inovasi dengan pelayanan kemitraan melalui aplikasi gobiz dan gopartner. Inovasi ini dilakukan agar gofood tetap mampu menjangkau gofood partner dan melaksanakan kemitraan tanpa adanya kontak fisik berlebihan. Pelaksanaan sistem kemitraan secara daring tersebut berperan penting terhadap komitmen gofood partner dalam menggunakan layanan secara konsisten. Sehingga, perlu dilakukan pengukuran terhadap tingkat kepuasan gofood partner pada masa pandemi ini.

Kepuasan merupakan perasaan senang atau kecewa pada seseorang yang muncul setelah membandingkan antara harapan atas produk tertentu dengan 
kenyataan yang diterima (Kotler, 2009). Kepuasan mitra terhadap sistem kemitraan dengan gofood artinya mengukur sejauh mana mitra sebagai pengguna produk merasa senang terhadap produk yang diterima. Tingkat kepuasan gofood partner sangat berperan penting terhadap kualitas pelayanan yang akan diberikan di masa mendatang sehingga mampu mempertahankan komitmen mereka dalam menggunakan layanan. Pengevaluasian terhadap suatu sistem atau prosedur operasional dapat dilakukan dengan metode pieces. Metode pieces merupakan alat analisis untuk menemukan permasalahan yang lebih spesifik dengan menggunakan aspek performance, information, economy, control, efficiency, dan service (Hidayatullah et al., 2020). Kerangka kerja pieces ditujukan sebagai alat mengevaluasi sistem yang digunakan sekarang dan melihat peluang sehingga dapat melakukan perbaikan ke depannya.

Tujuan dari penelitian ini adalah untuk mengukur tingkat kepuasan mitra gofood terhadap sistem kemitraan pada masa pandemi covid-19 di Kota Surabaya.

\section{METODE PENELITIAN}

Penelitian dilakukan di Kota Surabaya yang merupakan kota terbesar kedua setelah Kota Jakarta. Kota Surabaya dipilih karena menjadi ibu kota Propinsi
Jawa Timur sehingga kegiatan perekonomian masyarakat Jawa Timur berpusat di Kota Surabaya. Jenis penelitian ini menggunakan penelitian survei dan observasi yang dilaksanakan pada bulan Maret 2021. Populasi dalam penelitian ini adalah gofood partner yang terdiri dari mitra merchant sebagai pengusaha bisnis kuliner dan mitra driver sebagai ojek pengantar yang berlokasi di Kota Surabaya.

Dalam menentukan jumlah responden digunakan metode Quota Sampling, sampel yang dilakukan dengan cara mengambil subjek bukan didasarkan atas strata, tetapi jumlah yang sudah ditentukan (Arikunto, 2013). Penggunaan quota sampling sangat penting pada penelitian yang memiliki target individu yang spesifik (Lindner \& Dooley, 2008). Teknik ini biasanya digunakan pada populasi besar dengan pemilihan sampel yang didasarkan pertimbangan tertentu sesuai dengan ciri-ciri yang dikehendaki dan ditentukan sendiri sampai jumlah tertentu tanpa acak (Saleh, 2017). Pertimbangan ini menyesuaikan dengan kriteria pengambilan sampel yang dibutuhkan, antara lain merupakan mitra aktif gofood, sudah bermitra sejak sebelum pandemi, dan kriteria khusus merchant yaitu termasuk agroindustri makanan dan 
minuman yang menghasilkan produk hanya dengan satu kali proses pengolahan serta merupakan industri rumah tangga. Peneliti menggunakan total 30 sampel yang terdiri dari 15 responden mitra merchant dan 15 responden mitra driver, hal ini sejalan dengan pernyataan mengenai ukuran sampel yang layak dalam penelitian antara 30 sampai 500 (Sugiyono, 2017).

Data yang digunakan pada penelitian ini adalah data kualitatif yang berupa informasi dari pendekatan pieces. Metode pieces adalah kerangka yang digunakan dalam mengklasifikasikan suatu permasalahan pada bagian analisis dan perancangan suatu sistem (Ramadhani \& Kusuma, 2018). Kerangka kerja pieces dikembangkan James Wetherbe dengan tujuan untuk mengklasifikasikan suatu permasalahan (Bentley \& Whitten, 2007). Sehingga kerangka kerja pieces dapat digunakan sebagai pengukur tingkat kepuasan gofood partner terhadap sistem kemitraan yang baru diterapkan pada masa pandemi ini. Dimensi pengukuran PIECES terdiri dari :

\section{Performance}

Bagaimana performa atau kinerja dari sistem.

\section{Information}

Seberapa banyak dan seberapa jelas informasi yang didapatkan.

\section{Economics}

Apakah kualitas pelayan sebanding dengan biaya yang dikeluarkan.

\section{Control and Security}

Tingkat kesulitan penggunaan aplikasi dan keamanan yang terdapat pada sistem dan keamanan yang dirasakan selama bermitra

5. Efficiency

Apakah suatu variabel itu efisien atau tidak, dengan input yang sedikit bisa menghasilkan sebuah output yang memuaskan

6. Service

Bagaimana pelayanan yang dilakukan dan mengetahui permasalahan-permasalahan yang ada terkait tentang pelayanan (Hidayatullah et al., 2020)

Metode pieces menganalisis tingkat kepuasan dengan perhitungan nilai ratarata kepuasan dengan membagi antara jumlah skor setiap atribut dengan jumlah responden. Skor setiap atribut diperoleh menggunakan skala likert untuk mengukur pendapat seseorang mengenai suatu kondisi. Skor akan diberi nilai sebagai berikut : 
Tabel 1. Skor Kriteria Jawaban

\begin{tabular}{lcc}
\hline \multicolumn{1}{c}{ Jawaban } & Kriteria & Skor \\
\hline Sangat Setuju & SS & 5 \\
Setuju & S & 4 \\
Ragu-Ragu & R & 3 \\
Tidak Setuju & TS & 2 \\
Sangat Tidak & STS & 1 \\
Setuju & & \\
\hline
\end{tabular}

Total skor yang diperoleh dari survei selanjutnya akan dilakukan perhitungan rata-rata skor tiap atribut. Untuk mengetahui rata-rata skor dapat digunakan rumus berikut :

$$
R K=\frac{J S K}{J K}
$$

RK = Rata-rata skor

JSK = Total skor

$\mathrm{JK}=$ Jumlah kuisioner,

(Saptari \& Saptari, 2017)

Hasil perhitungan rata-rata selanjutnya dikategorikan tingkat kepuasan berdasar pada model Kaplan dan Norton sebagai berikut :
a. $1-1,79=$ Sangat tidak puas
b. $1,80-2,59=$ Tidak puas
c. $2,60-3,39=$ Ragu-ragu
d. $3,40-4,19=$ Puas
e. 4,20-5 = Sangat puas,

(Hadisaputro, et al, 2019)

\section{HASIL DAN PEMBAHASAN}

Data pada penelitian ini diperoleh melalui instrumen penelitian untuk mengukur objek penelitian. Data yang benar tergantung pada baik tidaknya instrumen penelitian yang dapat ditentukan dengan validitas dan reliabilitas. Validitas menunjukkan sejauh mana pengukuran tepat terhadap objek yang hendak diukur, sedangkan reliabilitas menunjukkan sejauh mana pengukuran dapat dipercaya (Arikunto, 2013). Hasil uji validitas pada instrumen penelitian ini dinyatakan valid karena semua $\mathrm{r}$ hitung $>\mathrm{r}$ tabel, dimana $\mathrm{r}$ tabel bernilai 0,361. Uji reliabilitas dinyatakan reliabel karena koefisien Cronbach's Alpha bernilai 0,759, koefisien berada diantara 0,70-0,90 (Yusup, 2018).

\section{Hasil Analisis Metode Pieces}

Pelaksanaan sistem kemitraan yang baru dengan daring ini dapat mempengaruhi loyalitas gofood partner dalam menggunakan layanan gofood. Faktor utama dalam mempertahankan loyalitas terhadap penggunaan produk adalah faktor kepuasan (Rahmawati, 2014). Tingkat kepuasan gofood partner mampu menerima dan beradaptasi dengan sistem. Tingkat kepuasan gofood partner dapat diukur dengan metode pieces yang terdiri dari aspek performance, information, economy, control, efficiency, dan service. 
Tabel 2. Hasil Perhitungan PIECES Mitra Merchant

\begin{tabular}{|c|c|c|c|}
\hline & No & Atribut & $\overline{\mathbf{Y}}$ \\
\hline \multirow{3}{*}{ Performance } & $\mathrm{P} 1$ & Penggunaan dan akses aplikasi gobiz mudah & \multirow{3}{*}{3,95} \\
\hline & $\mathrm{P} 2$ & Penerimaan pesanan melalui aplikasi mudah dilakukan & \\
\hline & P3 & $\begin{array}{l}\text { Kualitas sistem aplikasi yang disediakan perusahaan } \\
\text { berjalan dengan baik }\end{array}$ & \\
\hline \multirow{2}{*}{ Information } & $\mathrm{P} 4$ & $\begin{array}{l}\text { Informasi mengenai Restoran dan Produk yang ditampilkan } \\
\text { pada aplikasi gofood lengkap }\end{array}$ & \multirow{2}{*}{3,93} \\
\hline & P5 & $\begin{array}{l}\text { Ketepatan informasi yang tertera pada aplikasi gobiz } \\
\text { (akurat) }\end{array}$ & \\
\hline \multirow{4}{*}{ Economic } & P6 & Biaya jasa layanan tidak memberatkan mitra & \multirow{4}{*}{3,92} \\
\hline & P7 & Kecepatan sistem penarikan pendapatan (waktu) & \\
\hline & P8 & Ketepatan sistem penarikan pendapatan (jumlah) & \\
\hline & P9 & Pemberian apresiasi kepada mitra & \\
\hline \multirow{2}{*}{$\begin{array}{l}\text { Conntrol } \\
\text { Security }\end{array}$} & $\mathrm{P} 10$ & Menjaga kerahasiaan data pribadi mitra & \multirow{2}{*}{4,04} \\
\hline & P11 & Mitra merasa aman dalam menggunakan layanan gofood & \\
\hline \multirow{2}{*}{ Eficiency } & $\mathrm{P} 12$ & Efisiensi waktu, biaya, dan tenaga & \multirow{2}{*}{3,57} \\
\hline & $\mathrm{P} 13$ & Mempermudah mitra memperoleh pesanan & \\
\hline \multirow{3}{*}{ Services } & $\mathrm{P} 14$ & Prosedur pendaftaran mitra mudah dan jelas & \multirow{3}{*}{3,73} \\
\hline & $\mathrm{P} 15$ & Perusahaan dapat merespon keluhan dengan tanggap & \\
\hline & P16 & Layanan call unit dapat dihubungi dengan mudah & \\
\hline
\end{tabular}

Kepuasan mitra merchant dengan metode pieces diperoleh rata-rata skor total sebesar 3,86. Jika nilai tersebut dipadukan dengan tingkat kepuasan menurut Kaplan dan Norton, maka tingkat kepuasan mitra merchant termasuk dalam kategori puas. Hasil perhitungan rata-rata skor tiap aspek dapat dilihat pada Tabel 2, aspek performance menjadi aspek dengan nilai tertinggi kedua sebesar 3,95 dan dikategorikan puas. Kinerja pada aspek ini menunjukkan indikasi positif dan dirasa telah berperan baik bagi mitra. Aspek berikutnya adalah information dengan kategori puas dan hasil perhitungan rata- rata sebesar 3,93. Hasil tersebut menunjukkan bahwa mitra sudah merasa puas dengan informasi mengenai toko, produk yang ditawarkan, harga, serta driver yang akan mengantar produk mereka. Berdasarkan wawancara terdapat satu hal yang disayangkan oleh mitra dengan sistem yang baru yaitu mereka tidak memperoleh akses tentang informasi konsumen. Semua urusan yang berkaitan dengan konsumen harus dihubungkan melalui driver. Aspek economic memiliki rata-rata sebesar 3,92 artinya mitra telah terpuaskan. Pada kondisi ini yang paling menjadi masalah adalah perekonomian, 
namun dengan adanya kemitraan gofood ini ternyata memberikan pengaruh positif. Sebagian besar mitra mengaku bahwa gofood dapat mengembalikan pendapatannya seperti ketika sebelum PSBB. Selanjutnya aspek control \& security dengan nilai tertinggi yaitu 4,04 dan termasuk ke dalam kategori puas. Mitra tidak merasa khawatir dengan penggunaan aplikasi yang tersedia dan percaya terhadap perusahaan untuk menjaga data pribadi yang diberikan. Aspek efficiency dengan rata-rata 3,57 walaupun masih dikategorikan puas, aspek ini menjadi aspek dengan nilai terendah dibandingkan aspek lainnya. Pada aspek ini dengan sistem kemitraan baru terkait fitur super partner memang membantu mengembalikan kondisi penjualan mereka. Namun mitra merasa sedikit gelebah, karena tidak bisa membagi konsentrasinya untuk selalu memantau aplikasi. Aspek yang terakhir adalah service dengan hasil perhitungan rata-rata 3,73 yang menunjukkan bahwa mitra merasa puas terhadap aspek ini. Sistem kemitraan secara daring ini mewajibkan mitra menyampaikan keluhannya melalui mitra call unit sehingga mereka merasa kurang lega dalam menyampaikan keluhannya. Sebelum pandemi, penyampaian dapat dilakukan ketika penanggung jawab mereka datang, walaupun demikian mitra merasa pihak perusahaan mudah dihubungi.

Berdasarkan hasil pada Tabel 2, jika dibandingkan dengan penelitian Suprayitno et al. (2021) aspek performance, information, control \& security, efficiency, dan services mengalami penurunan yang semula berada pada kategori sangat puas menjadi puas. Menurut observasi yang dilakukan pada mitra, sistem kemitraan melalui daring ini merupakan hal yang baru bagi mereka. Sehingga, diperlukan waktu dalam beradaptasi dengan sistem tersebut. Terlebih lagi hingga saat ini perusahaan selalu memberikan fitur-fitur tambahan guna upaya meningkatkan penjualan mitra dan mendorong mitra selalu memperbarui serta mempelajari hal tersebut. 
Tabel 3. Hasil Perhitungan PIECES Mitra Driver

\begin{tabular}{|c|c|c|c|}
\hline & No & Atribut & $\overline{\mathbf{Y}}$ \\
\hline \multirow{3}{*}{ Performance } & $\mathrm{P} 1$ & Penggunaan dan akses aplikasi gopartner mudah & \multirow{3}{*}{4,13} \\
\hline & P2 & Penerimaan pesanan melalui aplikasi mudah dilakukan & \\
\hline & P3 & $\begin{array}{l}\text { Kualitas sistem aplikasi yang disediakan perusahaan berjalan } \\
\text { dengan baik }\end{array}$ & \\
\hline \multirow{2}{*}{ Information } & $\mathrm{P} 4$ & $\begin{array}{l}\text { Informasi mengenai Driver yang ditampilkan pada aplikasi } \\
\text { gofood lengkap }\end{array}$ & \multirow{2}{*}{4,00} \\
\hline & P5 & $\begin{array}{l}\text { Ketepatan informasi yang tertera pada aplikasi gopartner } \\
\text { (akurat) }\end{array}$ & \\
\hline \multirow{4}{*}{ Economics } & P6 & Biaya jasa layanan tidak memberatkan mitra & \multirow{4}{*}{$\mathbf{3 , 8 3}$} \\
\hline & $\mathrm{P} 7$ & Kecepatan sistem penarikan pendapatan (waktu) & \\
\hline & P8 & Ketepatan sistem penarikan pendapatan (jumlah) & \\
\hline & P9 & Pemberian bonus kepada mitra & \\
\hline \multirow{2}{*}{$\begin{array}{l}\text { Conntrol } \\
\text { Security }\end{array}$} & $\mathrm{P} 10$ & Menjaga kerahasiaan data pribadi mitra & \multirow{2}{*}{$\mathbf{3 , 8 3}$} \\
\hline & $\mathrm{P} 11$ & Mitra merasa aman dalam menggunakan layanan gofood & \\
\hline \multirow{2}{*}{ Eficiency } & $\mathrm{P} 12$ & Efisiensi waktu, biaya, dan tenaga & \multirow{2}{*}{ 3,94 } \\
\hline & $\mathrm{P} 13$ & Mempermudah mitra memperoleh pesanan & \\
\hline \multirow{3}{*}{ Services } & $\mathrm{P} 14$ & Prosedur pendaftaran mitra mudah dan jelas & \multirow{3}{*}{3,93} \\
\hline & $\mathrm{P} 15$ & Perusahaan dapat merespon keluhan dengan tanggap & \\
\hline & $\mathrm{P} 16$ & Layanan call unit center dapat dihubungi dengan mudah & \\
\hline
\end{tabular}

Hasil perhitungan kepuasan mitra driver dengan metode pieces diperoleh rata-rata skor total sebesar 3,94 berdasarkan tingkat kepuasan Kaplan dan Norton, maka tingkat kepuasan mitra driver dikategorikan puas. Hasil perhitungan rata-rata skor tiap aspek dapat dilihat pada Tabel 3, aspek performance menjadi aspek dengan nilai tertinggi sebesar 4,13 dan termasuk puas. Sama hal nya dengan mitra merchant, kualitas sistem pada aspek ini menunjukkan indikasi positif bahwa gofood berperan baik dalam hal kinerja yang diberikan oleh perusahaan. Aspek dengan rata-rata skor tertinggi berikutnya adalah information sebesar 4,00 dan masuk dalam kategori puas. Mitra merasa informasi yang ditampilkan mengenai dirinya sudah cukup baik dan lengkap. Selanjutnya aspek economic memiliki rata-rata sebesar 3,83 artinya mitra telah merasa puas dengan aspek ini. Aspek economic memiliki nilai terendah, menurut wawancara yang dilakukan pemanfaatan layanan gofood di masa pandemi belum berperan sebagai peningkat pendapatan driver, namun setidaknya dapat mengurangi pengangguran yang menjadi korban PHK untuk memiliki mata pencaharian lain. 
Aspek berikutnya control \& security dengan rata-rata 3,83 sehingga dikategorikan puas. Mitra merasa aman dalam menggunakan layanan yang disediakan. Aspek efficiency memperoleh perhitungan rata-rata 3,94 dengan kategori puas. Aspek efficiency berhubungan dengan aspek economic, mitra merasakan pengaruh yang menjadi kendala bagi mereka. Semakin banyaknya jumlah driver, maka semakin banyak pula pesaing yang mengakibatkan pendapatan mereka menurun (Giri \& Dewi, 2016). Hal tersebut terjadi karena pesanan yang masuk ke perusahaan harus dibagi rata sesuai jumlah mitra, sehingga pesanan yang mereka terima tidak sebanyak ketika sebelum pandemi. Aspek terakhir yaitu service dengan hasil perhitungan rata-rata 3,93 artinya mitra merasa puas terhadap aspek ini.

Berdasarkan hasil pada Tabel 3, jika dibandingkan dengan penelitian (Hadisaputro et al., 2019) aspek performance dan information mengalami penurunan yang semula berada pada kategori sangat puas menjadi puas, aspek economic meningkat dari ragu-ragu menjadi puas, dan selebihnya tetap di kategori puas. Menurut observasi yang dilakukan pada mitra, sistem kemitraan melalui daring ini dapat diadaptasi dengan baik oleh mitra, namun belum berpengaruh terhadap pendapatan driver.

\section{KESIMPULAN DAN SARAN}

Hasil analisis tingkat kepuasan gofood partner terhadap sistem kemitraan pada masa pandemi covid-19 di Kota Surabaya diperoleh bahwa mitra telah merasa puas, baik mitra merchant maupun mitra driver. Untuk tiap aspek pada kemitraan merchant memperoleh hasil antara lain aspek performance, information, economic, control \& security, efficiency, dan service tergolong dalam kategori puas. Tiap aspek pada mitra driver yaitu aspek performance, information, economic, control \& security, efficiency, dan service juga tergolong dalam kategori puas.

Saran yang dapat disampaikan pada penelitian ini diharapkan perusahaan lebih meningkatkan pelayanan kepada mitranya agar tingkat kepuasan mitra dapat meningkat pula, terutama terhadap aspek efficiency untuk mitra merchant dan aspek economics, control \& security untuk mitra driver.

\section{DAFTAR PUSTAKA}

Arikunto, S. 2013. Suatu Pendekatan Praktik. Jakarta: Rineka Cipta.

Bentley, Lonnie D, and Jeffrey L Whitten. 2007. Systems Analysis and Design 
for the Global Enterprise. New York: McGrawHill.

Dewi, Farah Eka. 2018. "Analisis Pengaruh Faktor Keamanan, Kemudahan, Dan Kepercayaan Terhadap Keputusan Pembelian Konsumen.".https://repository.ipb.a c.id/handle/123456789/94589

Giri, Putu Citrayani, and Made Heny Urmilla Dewi. 2016. "Analisis Faktor-Faktor Yang Mempengaruhi Pendapatan Driver Go-Jek Di Kota Denpasar." E-Jurnal EP Unud 6 (6): 948-75.

Hadisaputro, Elvin Leander, Wawan, and Erlin Setyaningsih. 2019. "Analisis Terhadap Kepuasan Mitra GO-JEK Driver Kota Balikpapan Menggunakan Framework PIECES." J-Sim : Jurnal Sistem Informasi 2 (April): 23-28. http://ojs.stmikborneo.ac.id/index.php/JSIm/article/view/32

Hidayatullah, Syarif, Irany Windhyastiti, and Ike Kusdyah Rachmawati. 2020. "Pieces Analysis: Means To Analyze The Satisfaction Of Transport Users In The City Of Malang" 9 (04).

Kotler, P. 2009. Manajemen Pemasaran. Jakarta: Erlangga.

Lee, Yen Nee. 2020. "How the Coronavirus Pandemic Has Hit the Global Economy." Cnbc, 2020.https://www.cnbc.com/2020/0 4/24/coronavirus-pandemicsimpact-on-the-global-economy-in7-charts.html

Lindner, James R., and Kim E. Dooley. 2008. "Using Non-Probability Sampling Methods in Agricultural and Extension Education
Research.” Journal of International Agricultural and Extension $\begin{array}{llll}\text { Education } & 15 & \text { (2): } 5 \text {. }\end{array}$ https://doi.org/10.5191/jiaee.2019.2 6105

Rahmawati, Rena. 2014. "Pengaruh Kepuasan Terhadap Loyalitas Pelanggan (Sebuah Kajian Terhadap Bisnis Makanan).” Teknobuga 1 (1): 66-79. https://journal.unnes.ac.id/nju/inde x.php/teknobuga/article/view/6404

Raj, Manav, Arun Sundararajan, and Calum You. 2020. "COVID-19 and Digital Resilience: Evidence from Uber Eats." SSRN Electronic Journal, 1-26. https://doi.org/10.2139/ssrn.362563 8

Ramadhani, Syahri, and Wahyu A. Kusuma. 2018. "PIECES Framework Untuk Analisa Tingkat Kepuasan Pengguna Dan Kepentingan Sistem Informasi." Jurnal Teknologi Dan Manajemen Informatika 4 (2). https://doi.org/10.26905/jtmi.v4i2.2 101

Saleh, Sirajuddin. 2017. Analisis Data Kualitatif. Bandung: Pustaka Ramadhan.

Saptari, Ari, and Mochamad Ari Saptari. 2017. "Analisa Dalam Mengukur Kualitas Pelayanan Terhadap Kepuasan Konsumen Menggunakan Metode PIECES" 6 (September): 39-47.

Sari, Silvia Dinan, and Anas Zaini. 2020. "Kesempatan Kerja Dan Pendapatan Pelaku Pemasaran Agribisnis Online Di Kota Mataram" 21 (2): 81-91. 
Severson, Kim and Yaffe-Bellany. 2020. Independent Restaurants Barace For The Unknown.https://www.nytimes.co $\mathrm{m} / 2020 / 03 / 20 /$ dining/localrestauran ts-coronavirus.html

Sugiyono. 2017. Penelitian kuantitatif, kualitatif dan R\&D. Bandung: CV Alfabeta.
Suprayitno, Dila Seltika Canta, and Adi Hermawansyah. 2021. "Analisis PIECES Framework Terhadap Kepuasan Mitra Go-Food Dalam Penggunaan Aplikasi Go-Biz Kota Balikpapan." 19-26. 